\title{
Equilibrium Tasks in Geography
}

Rubtzov V.A.

Kazan Federal University, Institute of Management, Economics and Finance, Kazan, 420008, Russia

Gabdrakhmanov N.K.

Kazan Federal University, Institute of Management, Economics and Finance, Kazan, 420008, Russia

Delabarr O.A.

Kazan Federal University, Institute of Management, Economics and Finance, Kazan, 420008, Russia

Tyabina D. V.

Kazan Federal University, Institute of Language, 420008, Kazan, Russia

\section{Doi:10.5901/mjss.2015.v6n3p669}

\begin{abstract}
While solving the task of analysis and predicting behaviour of any complex systems one of the main approach is the defining the sufficient stable state of such a system according to the indicators emphasized as the basic ones
\end{abstract}

Keywords: equilibrium, historical distinctness

\section{Introduction}

The historical distinctness of objective and subjective logic of social, ecological and economical relations development enables to reveal the essence of new quality in their development as law-tendency that guides and directs the flow of processes of stable improvement in modern conditions into the way of mutual adaptation of economical, natural and social sub systems of territorial system. The need for theoretical interpretation of the given tendency and practical acquirement is stipulated by the fact that large social and economical errors and irreplaceable loss stem from an inability (or reluctance) to predict the whole complex of possible consequences of economical activity on the territory and also because of set accustomed point of view about principal incompatibility of social welfare growth with ecological and economical equilibrium $[1,2,3]$.

The active manifestation of law of ecological and economical balance has the connection with the modern stage of natural and historical process namely because multidirectional development of opposite sides of unity (society and nature) is gaining mutually exclusive character [3,4]. But on the other hand the very modern conditions give the opportunity to society to change social and economical managerial mechanisms of territorial social ecological and economical systems. [5,6].

It is thought that the law of social, ecological and economical balance of territorial systems should have such definition: the law of ecological and economical balance expresses the necessary and stable public need for consciously preventive (warning and leading) maintenance of «working condition» of natural self-regulation mechanisms in an attempt to provide socially useful levels of quality and quantity of natural conditions and resources as the most important factors of human's and society's health, constant development of material manufacture, which are the natural grounds of social and economical progress.

The task of balanced development of ecological, economical and social processes, occurred on the given territory, cannot be done in the framework of traditional ecological and economical research, designated mainly to keep the homeostatic features of territorial systems $[7,8,9]$. Here it is necessary to transmit to practical acquirement of new methodology, methods that take the territory entirely as the most important natural economical0 and ecological resource in the modern society 
In economy the balance between demand and offer is traditionally the main principle for creating and defining equilibrium state $[10,11,12]$. Such condition of the balance can be detected by different ways.

\section{Method}

In the pattern of input-output balance the whole manufacturing in the system under review is divided into a fixed number (say, $n$ ) conditionally clear sectors, each of them produces one type of product. If we know industrial output (offer) $x_{i}$ for each $\mathrm{i}$-sector where $\mathrm{i}=1,2, \ldots, \mathrm{n}$, it is possible to estimate the cost of manufacturing (productive demand) on $i$-product through the size cost per unit aij

$Z_{i}=a_{i j} x_{j}=a_{i 1} x_{1}+\ldots+a_{i n} x_{n}$,

$j=1$

i.e. $a_{i j}$ is the amount of i-product, which is necessary to output item of $j$-product. The base for such a structure is the invariance factor of cost per unit in different period of time on the assumption of invariability of technology. In addition to productive demand $z_{i}$ there can be given the size of non-manufacturing costs (non-manufacturing demand) $\mathrm{c}_{j} 0$ for each $i$-product and in the result there should be the balance condition: $x_{j}=z_{i}+c_{j}$ where $i=1, \ldots, n$, or equivalent,

$\mathrm{n}$

$x_{j}=a_{i j} x_{j}=c_{j}$ для $i=1, \ldots, n$.

$j=1$

The major task is to estimate the size of product manufacturing $x_{i}$,providing the given value of productive demand $c_{j}$ for all $i=1, \ldots, n$. Thus, it is necessary to solve classical system of linear equation relative to unknown quantity $x_{i}$.

Let us illustrate the above by Walrasian linear model. Theoretically it proves the fact that giving formalized function of public welfare, depended on the resource state, in a given period of time, it is possible to find location strategy of natural resources that is optimal on selected criterion in a period of time adjucted to the total bulk of resourcers or its maximum permissible stream depending on the kind of resource.

This pattern consists of the following elements.

1. Technology

Ax $B, x$,

whree A - resource cost per unit matrix; $\mathrm{B}$ - resource capacity; $\mathrm{X}$ - make quantity.

2. effective demand:

$S_{j}=S_{j}(C, y) ; S \quad 0$,

where $\mathrm{S}_{\mathrm{j}}$ - product demand; $\mathrm{C}$ - product price vector; $\mathrm{y}$ - price vector on manufacturing resources and salary rate.

It is supposed that the demand functions are steady, differentiated, homogenous in degree of 0 and satisfy the axiom of revealed preference.

Economical equilibrium condition:

$\mathrm{CS}=\mathrm{yB}$,

that means the demand sector is on budget straight line, and the resource owners are about to spend the whole profit $B$ on the commodity purchase. The result is :

$C(S-x)=0$

$C 0$

$S-x \quad 0$,

that means, at first zero cost of extra produced commodity (if for certain $\mathrm{j}$ there is abundance compared tpo demand $x_{j}>S$, effects of a sale from this abundance $C_{j}\left(S_{j}-x_{j}\right)$ equals zero), secondly cost negativity on products and, thirdly product idleness in capacity exceeding the demand. Simultaneously

$y(A x-B)=0$, y 0

means, at first, profit of abundant resources equals zero, secondly cost of resources and rates are nonnegative.

\section{Conclusions}

In addition to the above it should be mentioned that in essence the law of ecological and econimical balance needs reflection of not only the existing delopment level of ecological and economical processes and relationship but the necessity of «leading reflection» as the way of providing long-term stable development of the society.

The notion of balance has rather apparent sense at level of intutition. It is easy to determine in terms of mechanics, for instance: «To keep the balance of the body that is accepted as a material point, resultant of all used forcesmust be 
equal zero». Besides value such a definition has an obvious disadvantage - the same notion can be formulated otherwise in more complex systems and traditional simplified understanding is the obstacle to its use in research and analysis of appearing tasks in these spheres

To generalize the notion of balance it is possible to use the existence quality of the researched system as whole. Usually the system state is detected by a set of characteristics and paremeters. If these meanings are in range that provides long-term functioning of the given system, it is possible to consider that the system is in balance. Thus, this condition can be both static and dynanic, i.e. it is (balanced) trajectory of system motion. To distinct such notions from the traditional ones these conditions may be labelled as generalized balance. On the basis of this notion of balance it is possible to formulate equilibrium approach to research of various compound systems in rather long periods of time. This approach will include defining the task of generalized balance for such a system in the form of mathematical model. Therefore there is a question on the conditions of existance of solution the received task, which indicate the conditions of stable existance of the system itself. The received task solution will indicate the states of the systems, i.e. it will enable to predict system behaviour. Besides there will be the oportunity to indentify the current states of the system in relation to balance state and the choice of levers for current state correction. So the problem involves a question to formulate the task of generalized balance in the form of the mathematical model.

This approach to modulate economical systems acquired significant development in the XX century, especially after the existence proof of equilibrium price for rather genaral mathematical market economy model, elaborated by K.J. Arrow and $G$ Debreu. However, the various attempts to make this appsroach based on the task solutuion

$D_{i}\left(p^{*}\right)=S_{i}\left(p^{*}\right)$ для всех I $=1, \ldots, n$, universal one and also to make it the only single tool of investigation in economy faced signigicant obstacles in actual economic system modulation and not to speak of objections of the economists (for example, Keynesians, institutionalists and others) and matehmaticians. Consequently there is an issue of generalization of such a balance notion on the one hand, and an issue of clearer cirle of taks that can be sloved on the based of the equilibrium approach on the other hand. It is quite heplful to use variation equation as a general mathematical model of different balance types.

The behaviour of complex system implies a great amount of parameters and relations, however it is probable to make quality conclusions on the based of comparatively small data in case there is certain signs of stationarity. Let us take the territorial item, its behaviour can be described by substantial factors of social, economical and geographical nature. The constant rational state among the factors define the signs of stationary behaviour, namely, size aij - increase of the meaning i-factor for fixed time period under single meaning j-factor - then it is invariable, though $a_{i j}$ can have even negative meaning, i.e. a decrease $\mathrm{i}$ - factor. Thus, if $\mathrm{x}=\left(\mathrm{x}_{1}, \ldots, \mathrm{x}_{\mathrm{n}}\right)^{\top}-\mathrm{a}$ set of factor meaning at the beginning of the time period, so

$$
y=x+A x=(1+A) x
$$

there is the proper set of meaning at the end of the period, where I - single matrix $n, A$ - squared matrix with an element $a_{i j}$ для $\mathrm{i}, \mathrm{j}=1, \ldots, \mathrm{n}$. Such an approach follows the famous to stucture the models of sructuring. intersectorial balance by V.V. Leontiev. Sizes $a_{i j}$ approximate the appropriate derivates, i.e. $a_{i j}\left(y_{i}-x_{i}\right) / x_{i}$. The supposition of invariability of $A$ matrix elements enables to raise a question of endless trajectories investigation $\left\{x^{k}\right\}$, defined by formula

$$
x^{k+1}=(I+A) x^{k}, x^{k} \quad 0, k=0,1, \ldots,(1)
$$

Also, it is a question of balanced system motion, which includes outlining such task soltutions, where $x^{k+1}=(1+) x^{k}, x^{k} \quad 0,>0, k=0,1, \ldots(2)$

Relations (2) mean that all major system factors change in balance. Obviously, the question of existing task solution (1) - (2) leads to a task of meaning itself and their own matrix's A vectors, furthermoreболеe it is necessary to fine the conditions undeder which matrix $A$ has its own positive conditions and nonnegative vectors.

According to the definition matrix A includes both positive and negative elements, however, it is natural to suppose that all diagonal elements $a_{i j}$ are positive and there is diagonal dominant quality in a weak form, i.e. there are numbers $>0, i=1, \ldots, n$, so that

$a_{i 1}$ । $>\left|a_{i j}\right| x_{j}$, для $i=1, \ldots, n$.

j 1

It means that any factor bears the strongest influence itself, though it is a positive one. So the given matrix $A$ is $P$ matrix, i.e. all its major minors are positive and, and all its substantial meanings are also positive. Thus, if $n$ - odd numver, so matrix $A$ has al least one positive meaning. As a result the opriginal task leads to task solution

$A x=x, x 0, x 0,(3)$

Which give us the starting meaning $x^{0}$ of the trajectory out of (1),providing balanced system behaviour. The existence of such solutions says about the possibility of stable development study of a distributed system and indicates access to a corresponding stationary regime. If the system contains several subsystems, defined by geography, it is 
possible to conduct a similar study in a wider context.

Regarding each of the i-region as an indeoended one, we can receive the proper meanings (i) and $x^{(i)}$ and compare them. If the regions have close connections, it is possible to create a common matrix of changes factors $A$, which will have more common, rather than block and diagonal, form, assuming nonzero elementsw outsde the blocks. The solution of the problem of their own values and their own vectors will show the capabilities of the output of the entire system at the stationary regime. In the case when the matrix a has several positive eigenvalues and corresponding vectors, there are multiple steady States, of which it is possible to choose the most rational.

\section{References}

Gabdrakhmanov N.K., Rubtzov V.A., Shabalina S.A., Rozhko M.V.,. Kucheryavenko D.Z The role of territorial organization of cities in the touristic attraction of the region on the example of the Republic of Tatarstan // Life Science Journal 2014;11(11), Pages 451-455.

Safiullin, L.N., Gafurov, I.R., Shaidullin, R.N., Safiullin, N.Z. Socio-economic development of the region and its historical and cultural heritage // Life Science Journal 11 (6 SPEC. ISSUE), 2014, pp. 400-404

Gabdrakhmanov N.K. and M.V. Rozhko Positioning of Volga Federal District Regions by Demographic Situation Index // World Applied Sciences Journal, Volume 30 Number 6, 2014. - Pages 792-795.

Bagautdinova, N.G., Safiullin, L.N., Badrtdinov, N.N. The role of consumer expenses in ensuring forward dynamics of the Russian economy // Mediterranean Journal of Social Sciences 5 (12), 2014, pp. 43-48

Gabdrakhmanov, N.K. and V.A. Rubtsov, 2014. Tourist and Recreational Positioning of Tatarstan Republic: Cluster Analysis. World Applied Sciences Journal, 30(Management, Economics, Technology \& Tourism): Pages 202-205.

Mingaleva, Z., Bunakov, O. Innovative ways of using the tourist potential as the basis of territories development // Life Science Journal. Volume 11, Issue 6 SPEC. ISSUE, 2014, Pages 315-317.

Gabdrakhmanov, N.K. and V.A. Rubtzov, 2014. Geodemographic Polarization Processes: Municipal Level (The Case of the Kukmorsky Municipal District of the Republic of Tatarstan). World Applied Sciences Journal, 30(10): Pages 1317-1320.

N.K. Gabdrakhmanov, V.A. Rubtsov. The Objects of Social Infrastructure in the Social Image of the Region Shaping // Procedia - Social and Behavioral Sciences 140 ( 2014 ) 419 - 421

Komarova, V.N., Zjablova, O.V., Denmukhametov, R.R. An infrastructure factor in regional competitiveness // Mediterranean Journal of Social Sciences, 5 (18 SPEC. ISSUE), 2014, pp. 355-360 